\title{
Erratum to: Neonatal Microsurgical Repair of a Congenital Abdominal Aortic Aneurysm with a Cadaveric Graft
}

\author{
Annie Le-Nguyen ${ }^{1, *}$ Shahrzad Joharifard ${ }^{2, *}$ Geneviève Côté ${ }^{3}$ Daniel Borsuk ${ }^{4}$ Rafik Ghali ${ }^{5}$ \\ Michel Lallier ${ }^{2}$
}

${ }^{1}$ Department of Surgery, Division of General Surgery, Saint Justine Hospital, Montreal, Quebec, Canada

${ }^{2}$ Department of Surgery, Division of Pediatric Surgery, Saint Justine Hospital, Montreal, Quebec, Canada

${ }^{3}$ Department of Anesthesiology, Saint Justine Hospital, Montreal, Quebec, Canada

${ }^{4}$ Department of Surgery, Division of Plastic Surgery, Saint Justine Hospital, Montreal, Quebec, Canada

${ }^{5}$ Department of Surgery, Division of Vascular Surgery, Hôpital

Maisonneuve-Rosemont, Montreal, Quebec, Canada

European J Pediatr Surg Rep 2021;9:e50.
Address for correspondence Annie Le-Nguyen, Department of Surgery, Division of General Surgery, Saint Justine Hospital, Montreal, Quebec, H3T 1C5, Canada (e-mail: annie.le-nguyen@umontreal.ca).

ERRATUM

Authors of the above-mentioned article DOI: 10.1055/s-0041-1723019; published online on March 3, 2021) have informed that the first two authors share equal authorship for the article. The information has been updated in the article.

\footnotetext{
* Both authors contributed equally to the manuscript.
}

DOI https://doi.org/

$10.1055 / \mathrm{s}-0041-1730902$

ISSN 2194-7619.

\section{(c) 2021. The Author(s).}

This is an open access article published by Thieme under the terms of the Creative Commons Attribution License, permitting unrestricted use, distribution, and reproduction so long as the original work is properly cited. (https://creativecommons.org/licenses/by/4.0/)

Georg Thieme Verlag KG, Rüdigerstraße 14, 70469 Stuttgart, Germany 